\section{PENGENALAN MEDIA PEMBELAJARAN DARING BERBASIS STEM UNTUK GURU IPA DI SMAN 9 BANDAR LAMPUNG}

Indah Oktaviani ${ }^{*}$, Ika Agus Rini², Mia Maria Ulfah ${ }^{3}$, Ahmad Dodi Andriana ${ }^{4}$

1,2,3,4 Institut Teknologi Sumatera

* Indah Oktaviani

Email : indah.oktaviani@bi.itera.ac.id

\begin{abstract}
The learning process in schools was carried out online because of the spread of the Covid-19 pandemic. It requires teachers to be more creative in handling technology-based learning media to be more interactive, especially in pandemic conditions. However, not many teachers in schools master software as a learning medium, so it is necessary to conduct training in adopting technology in distance learning. The method implemented includes design and preparation, including a survey of the teacher's condition in utilizing learning media, implementing activities, and evaluating. The preliminary survey results showed that science teachers were still very limited in utilizing learning methods with interactive software. The training was carried out with modules provided and required software that could represent STEM-based sciences learning using Nearpod and PhET simulation virtual laboratories. The training results showed an increase in the understanding and creativity of Mathematics and Natural Sciences teachers in the online learning process.
\end{abstract}

Keywords: training, teacher, distance learning, neared, PhET

\begin{abstract}
Abstrak
Meluasnya pandemi Covid-19 memaksa proses pembelajaran di sekolah dilakukan secara daring. Hal ini menuntut guru untuk lebih kreatif dalam menggunakan media pembelajaran yang berbasis teknologi agar pembejaran lebih interaktif terutama pada kondisi pandemi. Akan tetapi tidak banyak guru di sekolah yang menguasi perangkat lunak sebagai media pembejaran, sehingga perlu dilakukan pelatihan dalam pemanfaatan teknologi dalam Pembelajaran Jarak Jauh. Metode yang dilakukan antara lain perancangan dan persiapan yang meliputi survei terhadap kondisi guru dalam memanfaatkan media pembelajaran, pelaksanaan kegiatan, dan evaluasi. Hasil survei awal menunjukkan bahwa guru IPA masih sangat terbatas dalam memanfaatkan metode pembelajaran dengan perangkat lunak interaktif, sehingga dilakukan pelatihan dengan modul yang sudah disediakan dan perangkat lunak yang dapat mewakili pembelajaran IPA berbasis STEM dengan penggunaan Nearpod dan Laboratorium virtual simulasi PhET. Hasil Pelatihan menunjukkan adanya peningkatan pemahaman dan kreatifitas guru IPA dalam proses pembelajaran daring

Kata Kunci: pelatihan, PJJ, guru, nearpod, PhET
\end{abstract}


PENGENALAN MEDIA PEMBELAJARAN DARING BERBASIS STEM UNTUK GURU IPA DI SMAN 9

BANDAR LAMPUNG

Indah Oktaviani, Ika Agus Rini, Mia Maria Ulfah, Ahmad Dodi Andriana

Volume 1, No. 1, April 2021 hal. 77-88

DOI Artikel : 10.46306/jub.v1i1.16

\section{PENDAHULUAN}

Munculnya wabah Covid-19 di Indonesia pada awal tahun 2020 membawa perubahan dalam proses pembelajaran. Aktivitas pembelajaran tatap muka beralih ke pembelajaran pembelajaran jarak jauh (PJJ) atau daring secara mendadak. Hal ini harus dilakukan untuk mencegah penyebaran Covid-19. Era Industri 4.0 dengan perkembangan teknologi dan komunikasi yang cepat telah memiliki pengaruh yang besar terhadap proses pengajaran dan pembelajaran, seperti adanya fasilitas sistem electronic learning (e-learning) yang menggunakan layanan elektronik sebagai alat bantunya. Namun tidak semua sekolah memiliki Sumber Daya Manusia (SDM) yang dapat menggunakan teknologi tersebut. Baik guru, maupun peserta didik sendiri banyak mengalami kesulitan dalam memanfaatkan teknologi tersebut dalam masa PJJ ini. Terlebih lagi pelatihan-pelatihan terkait juga sulit untuk dilakukan karena adanya himbauan physical distancing. Selain itu, meskipun dilaksanakan secara dalam jaringan (daring), setiap metode pembelajaran tetap harus mengandung rumusan pengorganisasian bahan pengajaran, strategi penyampaian, dan pengelolaan kegiatan dengan memperhatikan faktor tujuan belajar, hambatan belajar, karakteristik peserta didik, agar dapat diperoleh efektivitas, efisiensi, dan daya tarik pembelajaran (Miarso, 2004). Penyampaian materi melalui daring sebenarnya dapat bersifat interaktif jika dikemas secara ideal dan memanfaatkan teknologi pada masa kini sehingga peserta belajar mampu berinteraksi dengan perangkat lunak yang dapat digunakan di komputer maupun telepon genggam sebagai media belajarnya. Hal ini tentunya tidak bisa lepas dari peranan guru sebagai fasilitator di kelas. Media pembelajaran memiliki manfaat dalam meningkatkan kualitas proses pembelajaran, aktivitas, motivasi belajar peserta didik dan meningkatkan hasil belajar siswa. Media pembelajaran merupakan suatu teknologi pembawa pesan yang dapat digunakan untuk keperluan pengajaran (Rusman, 2013). Media pembelajaran merupakan sarana fisik dan sarana komunikasi untuk menyampaikan materi (Suryadi \& Rosa, 2020). Media yang dikenal dalam pembelajaran sangat beragam.

Variasi penggunaan media pembelajaran dalam proses belajar mengajar memiliki beberapa manfaat diantaranya: (I) Pengajaran akan lebih menarik perhatian siswa sehingga dapat menumbuhkan motivasi belajar siswa, (2) Bahan pengajaran akan lebih jelas sehingga siswa dapat memahami dan menguasai tujuan pengajaran dengan baik, (3) Metode mengajar akan lebih bervariasi, (4) Siswa akan lebih banyak melakukan interaksi dalam kegiatan belajar sebab tidak hanya mendengarkan penjelasan guru tetapi juga aktivitas lain seperti mengamati, mendemonstrasikan dan lain - lain (Sung dkk, 2016), sehingga proses pembelajaran dapat terjadi dua arah. Oleh sebab itu penerapan teknologi dan informasi untuk PJJ sangat diperlukan dalam upaya meningkatkan hasil luaran belajar pada siswa. Pentingnya pembelajaran daring dengan pemanfaatan teknologi terutama di masa pandemic seperti saat ini untuk pembelajaran IPA memaksa pendidik untuk memiliki kemampuan dalam mengoperasikan teknologi tersebut. Akan tetapi masih sangat sedikit guru IPA yang dapat memanfaatkan perangkat lunak dalam proses pembelajaran daring. Proses pembalajaran IPA selain interaktif juga diperlukan peningkatan kemampuan keterampilan di laboratorium, yangmana tidak mungkin dilaksanakan dimasa pandemi. 
PENGENALAN MEDIA PEMBELAJARAN DARING BERBASIS STEM UNTUK GURU IPA DI SMAN 9

BANDAR LAMPUNG

Indah Oktaviani, Ika Agus Rini, Mia Maria Ulfah, Ahmad Dodi Andriana

Volume 1, No. 1, April 2021 hal. 77-88

DOI Artikel : 10.46306/jub.v1i1.16

Oleh sebab itu perlu adanya alternatif pembelajaran yang harus dikembangkan oleh guru dalam menyampaikan materi IPA. Salah satu metode pembelajaran interaktif adalah yang dapat mengintergrasikan media berbasis android yang terdapat unsur audio dan visual sehingga siswa lebih mudah memahami materi pelajaran (Maula \& Fatmawati, 2020). Metode pembelajaran tersebut dapat dilaksanakan dengan implementasi STEM (Science, Technology, Engineering and Mathematics). STEM adalah metode berfikir yang melibatkan integrasi pada beberapa mata pelajaran yaitu sains, matematika, teknik dan teknologi menjadi satu bidang pembelajaran baru yang sesuai untuk diajarkan di sekolah (Ayob dkk, 2017). STEM digunakan untuk meningkatkan keterampilan dan kemampuan pada peserta didik sehingga pembelajaran daring tidak monoton dan hanya berjalan satu arah.

Media yang dapat digunakan untuk pembelajaran interaktif di bidang IPA (Matematika, Fisika, Kimia, dan Biologi) diantaranya adalah Nearpod dan laboratorium simulasi PhET (Physic Education and Technology). Penggunaan kedua aplikasi tersebut sebagai media pembelajaran diharapkan dapat meningkatkan hasil pembelajaran dibandingkan proses pembelajaran yang hanya menggunakan kelas virtual tanpa dintegrasikan dengan perangkat lunak lainnya. Integrasi keduanya dapat memberikan efektifitas pembelajaran karena menggabungkan antara metode ceramah, belajar mandiri, kooperatif, dan pembelajaran berbasis permainan (Nasution, 1990). Laboratorium simulasi PhET merupakan salah satu simulasi laboratorium virtual yang dibuat oleh Universitas Colorado, Amerika Serikat. Laboratorium virtual memiliki beberapa keunggulan yaitu dapat mempermudah proses pembelajaran dan dapat diakses kapanpun dan dimanapun (Zacharia \& Jong, 20I4; Muflika \& Setiadi, 20I2). Sedangkan Nearpod juga merupakan perangkat lunak berbasis android yang sudah terintegrasi dengan system pembelajaran audio visual sehingga dapat digunakan dalam PJJ. Hasil penelitian menunjukkan bahwa fitur-fitur dari Nearpod untuk mempresentasikan dan mengajukan pertanyaan (Real-Time Asesment) oleh siswa sebagai hal yang paling mendorong mereka untuk terlibat dalam kegiatan pembelajaran di kelas. Selain itu, cara kontrol materi Nearpod membantu pendidik dalam tugas pembelajaran (Hakami, 2020). Berdasarkan permasalahan di atas dan adanya beberapa teknologi yang dapat digunakan dalam PJJ secara gratis, maka perlu dilakukan pelatihan atau bimbingan teknis untuk guru-guru IPA terkait pemanfaatan perangkat lunak tersebut. Hal ini akan menjadi salah satu alternatif dan terobosan dalam metode pembelajaran daring dengan pemanfaatan teknologi pada situasi pandemi maupun di masa depan. Dengan adanya laboratorium virtual simulasi PhET dan metode pembelajaran interaktif dengan Nearpod diharapkan dapat meningkatkan kreatifitas guru dan siswa dalam melaksanakan ide-ide pembelajaran sehingga luaran pembelajaran dapat tercapai dengan baik.

\section{METODE PENGABDIAN}

Kegiatan dilaksanakan pada bulan Oktober-November 2020 bermitra dengan Guru IPA di SMA Negeri 9 Bandar Lampung, Kota Bandar Lampung. Sebanyak 23 orang Guru IPA (Fisika, Kimia, dan Biologi) mengikuti kegiatan pelatihan untuk meningkatkan pengetahuan dan kemampuan dalam menggunakan media pembelajaran yang interaktif. Metode yang digunakan dalam kegiatan dilakukan dalam beberapa 
PENGENALAN MEDIA PEMBELAJARAN DARING BERBASIS STEM UNTUK GURU IPA DI SMAN 9

BANDAR LAMPUNG

Indah Oktaviani, Ika Agus Rini, Mia Maria Ulfah, Ahmad Dodi Andriana

Volume 1, No. 1, April 2021 hal. 77-88

DOI Artikel : 10.46306/jub.v1i1.16

tahap, dimana tahap awal adalah pengumpulan data awal terkait pemahaman guru menggunakan survey online dan dilanjutkan dengan praktikum secara langsung (luring), diawali dengan Ceramah untuk menyampaikan materi tentang pengenalan dan penerapan platform, Demonstrasi yang dilakukan oleh tim pengabdi sebagai narasumber untuk mempraktekkan penerapan teknologi dalam pembuatan sarana pembelajaran, serta Praktek yang dilakukan oleh guru secara langsungberdasarkan demonstrasi sebelumnya oleh tim pengabdian. Setelah itu dilakukan monitoring dan evaluasi untuk melihat hasil pelatihan. Secara garis besar langkah kegiatan PkM dilaksanakan dengan detail sebagai berikut:

\section{Perencanaan dan Persiapan}

Kegiatan perencanaan diperlukan untuk mengetahui kebutuhan guru IPA di SMAN 9 Bandar Lampung yang menjadi dasar dari penyusunan program. Tahapan penyusunan Program meliputi persiapan tim, survei lokasi dan sosialisasi, survei perkembangan materi, dan penerapan yang dilakukan selama ini.

\section{Pelaksanaan}

Pelatihan dilaksanakan secara bertahap melalui sosialisasi tatap muka secara langsung sesuai dengan protocol kesehatan, pengelompokan guru sesuai bidang ilmu, dan pemberian materi yang dipandu secara langsung oleh tim pengabdian beserta contoh proyek sains mandiri dengan menggunakan Nearpod dan LKS sederhana PhET. Hasil pemahaman dari peserta pelatihan kemudian dimonitoring untuk mengetahui kendala dalam proses pelaksaan program, dan mencari solusi terhadap masalah yang ada.

\section{Evaluasi}

Evaluasi keberhasilan kegiatan dilakukan untuk mengetahui kekurangan dalam pelaksanaan program. Melalui proses evaluasi, kekurangan yang terjadi dalam pelaksanaan program dapat diperbaiki menjadi lebih baik. Tahap ini dilakukan oleh tim bersama stakeholder (SMAN 9 Bandar Lampung) dan terintegrasi pada tahapan pelaksanaan. Adapun detail pelaksanaan dan evaluasi tercantum pada tabel I. 
PENGENALAN MEDIA PEMBELAJARAN DARING BERBASIS STEM UNTUK GURU IPA DI SMAN 9

BANDAR LAMPUNG

Indah Oktaviani, Ika Agus Rini, Mia Maria Ulfah, Ahmad Dodi Andriana

Volume 1, No. 1, April 2021 hal. 77-88

DOI Artikel : 10.46306/jub.v1i1.16

Tabel I. Tahapan Pelaksanaan kegiatan PkM

\begin{tabular}{|c|c|c|c|c|}
\hline No. & Tahapan & Materi/Kegiatan & Metode & Tempat \\
\hline \multirow[t]{14}{*}{$\mathbf{I}$} & \multirow[t]{3}{*}{ Pembukaan } & Sambutan dari ketua tim & \multirow[t]{3}{*}{ Ceramah } & Perpustakaan \\
\hline & & PkM dan Wakil Kepala & & SMAN 9 BDL \\
\hline & & Sekolah & & \\
\hline & \multirow[t]{2}{*}{ Pretest } & Pengukuran tingkat & \multirow[t]{2}{*}{ Kuisioner } & \\
\hline & & pemahaman guru & & \\
\hline & \multirow{2}{*}{$\begin{array}{l}\text { Penjelasan dan } \\
\text { pengenalan }\end{array}$} & Memberikan materi dan & \multicolumn{2}{|l|}{ Ceramah, } \\
\hline & & memperkenalkan fitur-fitur & \multicolumn{2}{|l|}{ Demonstrasi, dan } \\
\hline & Nearpod & Nearpod & \multicolumn{2}{|l|}{ Praktek } \\
\hline & Penjelasan dan & Memberikan materi dan & \multicolumn{2}{|l|}{ Ceramah, } \\
\hline & pengenalan Lab. & memperkenalkan Lab. & \multicolumn{2}{|l|}{ Demonstrasi, dan } \\
\hline & Virtual Simulasi & Virtual Simulasi PhET & \multicolumn{2}{|l|}{ Praktek } \\
\hline & \multicolumn{4}{|l|}{ PhET } \\
\hline & \multicolumn{2}{|l|}{ Evaluasi Tahap } & \multicolumn{2}{|l|}{ Diskusi, dan Tanya } \\
\hline & \multicolumn{2}{|l|}{ pertama } & \multicolumn{2}{|l|}{ Jawab } \\
\hline \multirow[t]{2}{*}{2} & Evaluasi Tahap & & \multirow[t]{2}{*}{ Diskusi } & \multirow[t]{2}{*}{ Via Zoom } \\
\hline & kedua & & & \\
\hline \multirow[t]{4}{*}{3} & Monitoring dan & Pengumpulan tugas hasil & \multirow{4}{*}{$\begin{array}{l}\text { Diskusi, Tanya Jawab, } \\
\text { dan Kuisioner }\end{array}$} & Via WA \\
\hline & Evaluasi & pelatihan dari MGMP & & Group \\
\hline & menggunakan & & & \\
\hline & Post test & & & \\
\hline
\end{tabular}

\section{PELAKSANAAN DAN PEMBAHASAN}

Kegiatan pelatihan dilaksanakan baik secara daring maupun luring sesuai dengan jadwal pelaksanaan dan evaluasi (tabel I). Pelaksanaan utama dilaksanakan secara luring di perpustakaan SMAN 9 Bandar Lampung dengan total peserta 23 orang. Tim pengabdian menyiapkan modul dan juga video tutorial yang dibuat sebagai alat bantu untuk mendukung kelancaran pelaksanaan dan mempermudah peserta dalam memahami penjelasan dan praktik yang dilakukan (gambar I). Video tutorial juga diharapkan dapat membantu para guru untuk bisa mengulang kembali materi yang sudah disampaikan pada kegiatan secara daring. 
Indah Oktaviani, Ika Agus Rini, Mia Maria Ulfah, Ahmad Dodi Andriana

Volume 1, No. 1, April 2021 hal. 77-88

DOI Artikel : 10.46306/jub.v1i1.16

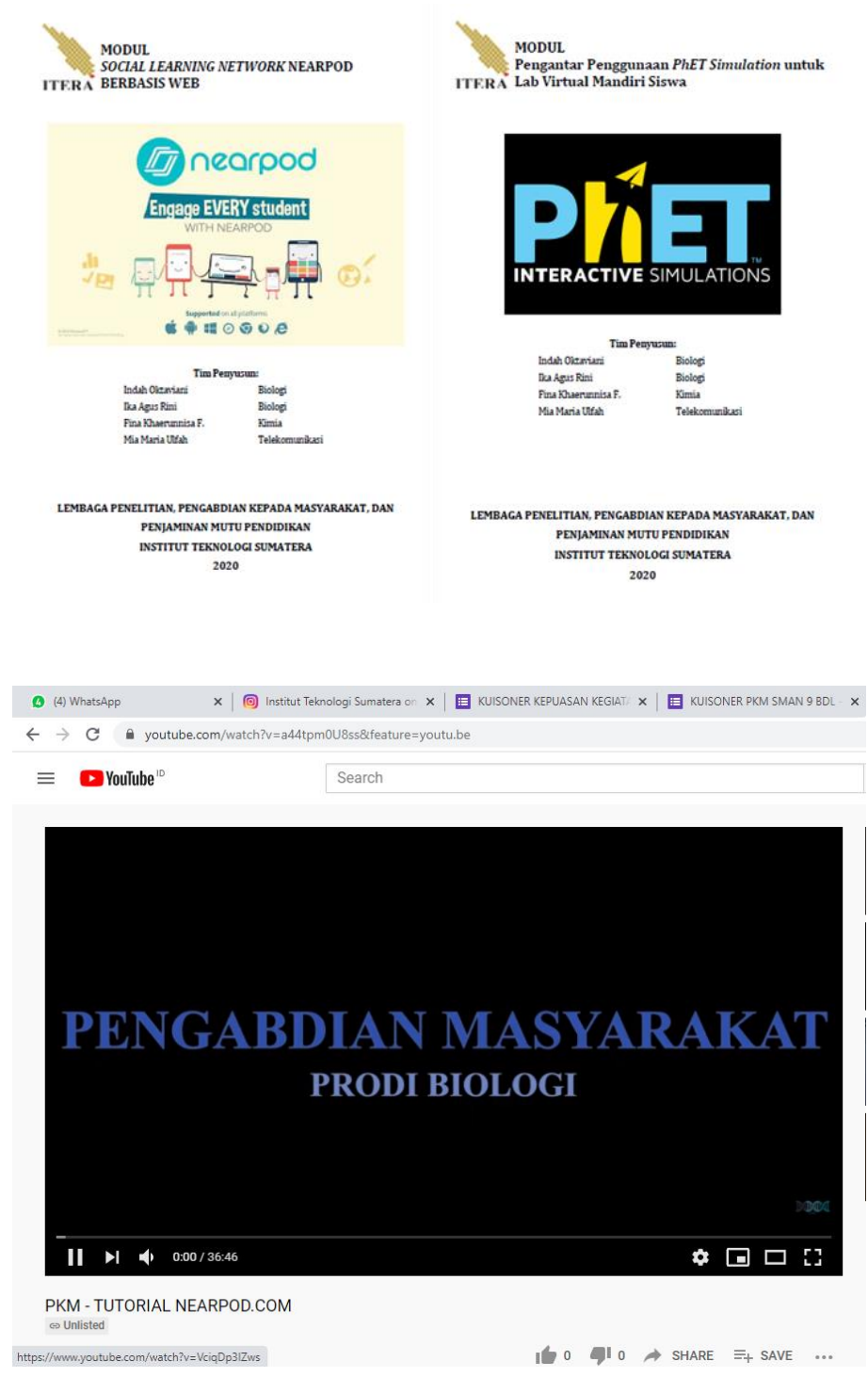

\section{Gambar I. Modul dan video yang digunakan dalam pelaksanaan PkM}

Para Guru yang mengikuti pelatihan ini sangat antusias pada saat praktik langsung. Setelah demonstrasi guru-guru diharapkan dapat mengimplementasikan pelatihan dengan membuat tugas yang diberikan oleh tim pengabdian. Tugas berupa pembuatan media pembelajaran menggunakan nearpod dan juga bahan ajar berupa lembar kerja siswa menggunakan Laboratorium Virtual PhET yang dapat diintegrasikan dengan Google Classroom ataupun juga Nearpod. Selama pembuatan tugas, guru dan tim pengabdian terus menjaga komunikasi melalui Zoom juga grup WA. Dokumentasi kegiatan bisa dilihat pada Gambar 2 dan gambar 3. 
Indah Oktaviani, Ika Agus Rini, Mia Maria Ulfah, Ahmad Dodi Andriana

Volume 1, No. 1, April 2021 hal. 77-88

DOI Artikel : 10.46306/jub.v1i1.16
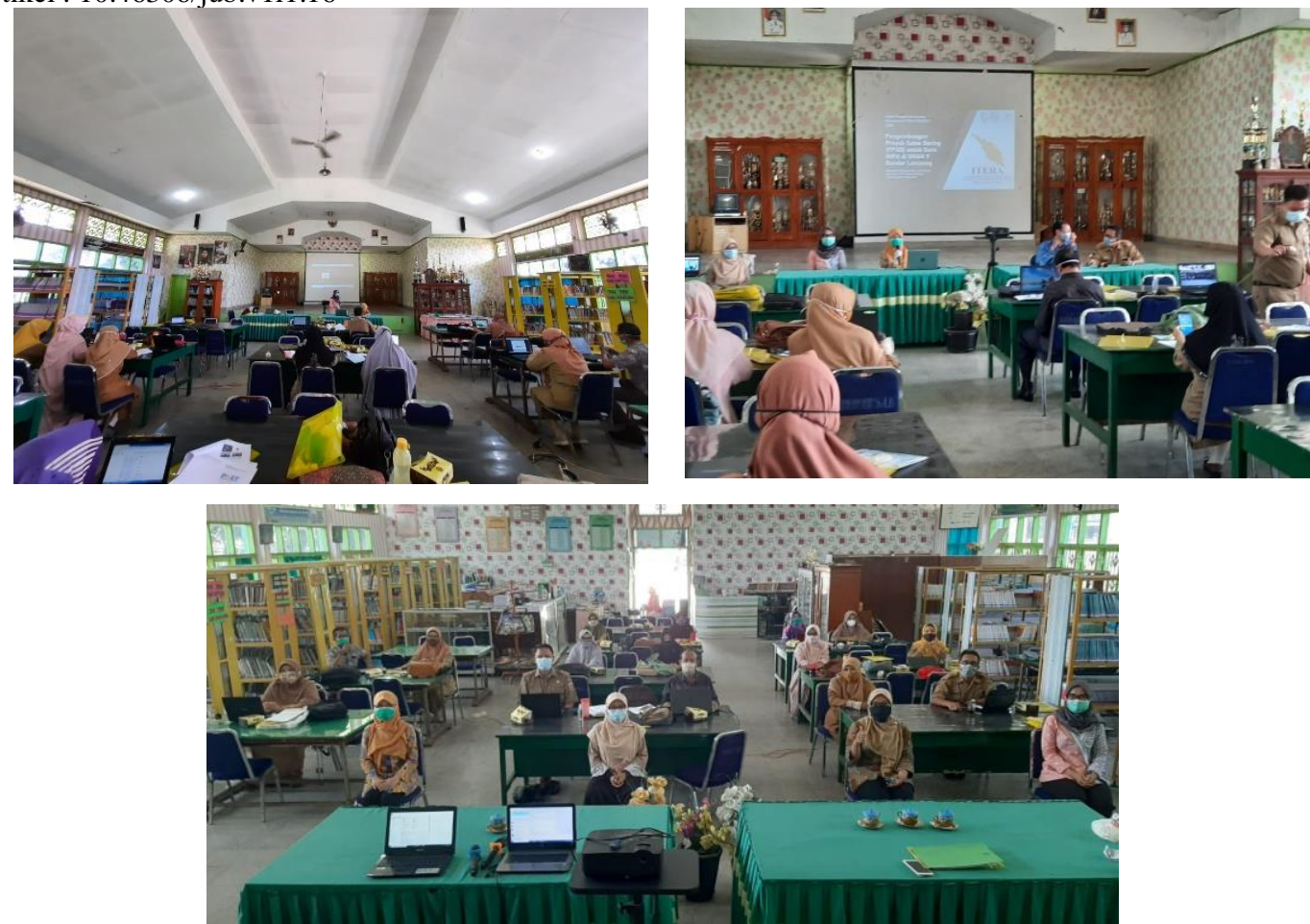

Gambar 2. Dokumentasi kegiatan luring selama pelatihan bersama para guru SMAN 9 Bandar Lampung

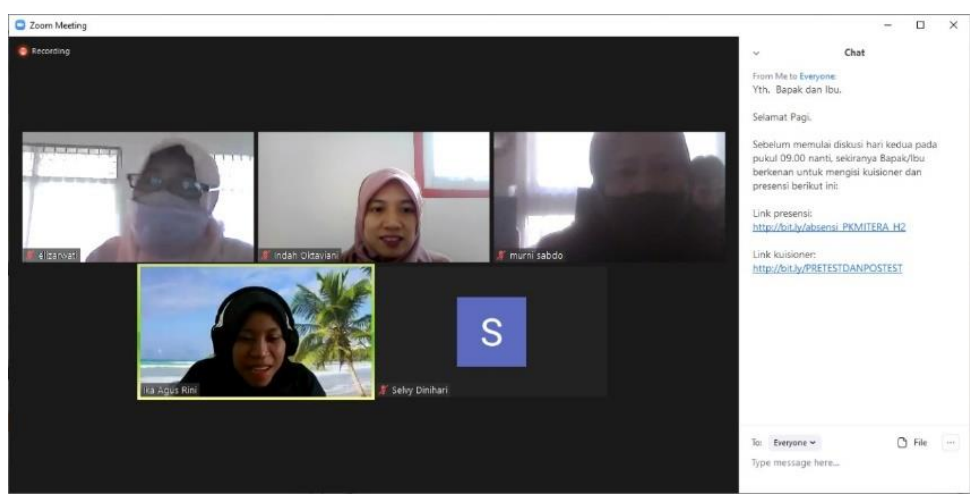

\section{Gambar 3. Screenshot zoom meeting saat tindak lanjut pelatihan dilakukan.}

Setelah mengikuti pelatihan tidak semua guru langsung memahami penggunaan kedua platform, dikarenakan memang dibutuhkan waktu yang lebih lama lagi untuk bisa memahami penggunaannya terutama dalam ketrampilan penggunaan fitur-fitur yang ada karena kemampuan Bahasa Inggris guru masih terbatas. Untuk meningkatkan pemahaman, maka peserta pelatihan ini diberi tugas untuk membuat contoh pembelajaran menggunakan kedua platform dan mengintegrasikannya dengan mata pelajaran sehingga peserta bisa praktek secara langsung. Sebagian besar peserta sudah mulai bisa menggunakan kedua platform walaupun ada beberapa yang masih perlu bimbingan (hasil pembuatan 
PENGENALAN MEDIA PEMBELAJARAN DARING BERBASIS STEM UNTUK GURU IPA DI SMAN 9

BANDAR LAMPUNG

Indah Oktaviani, Ika Agus Rini, Mia Maria Ulfah, Ahmad Dodi Andriana

Volume 1, No. 1, April 2021 hal. 77-88

DOI Artikel : 10.46306/jub.v1i1.16

tugas, gambar 4 dan gambar 5). Berdasarkan hasil tugas yang diberikan para guru cukup mampu membuat media pembelajaran yang interaktif dengan menggunakan fasilitas yang tersedia di Nearpod. Pembuatan LKS untuk penggunaan Laboratorium Virtual PhET juga sudah memenuhi aspek yang dibutuhkan untuk menuntun siswa belajar mandiri, seperti adanya pengantar, tujuan, dan langkah kerja yang cukup sistematis dan menarik disertai gambar penuntun. Hasil tugas dapat dilihat pada gambar 4 dan gambar 5 .
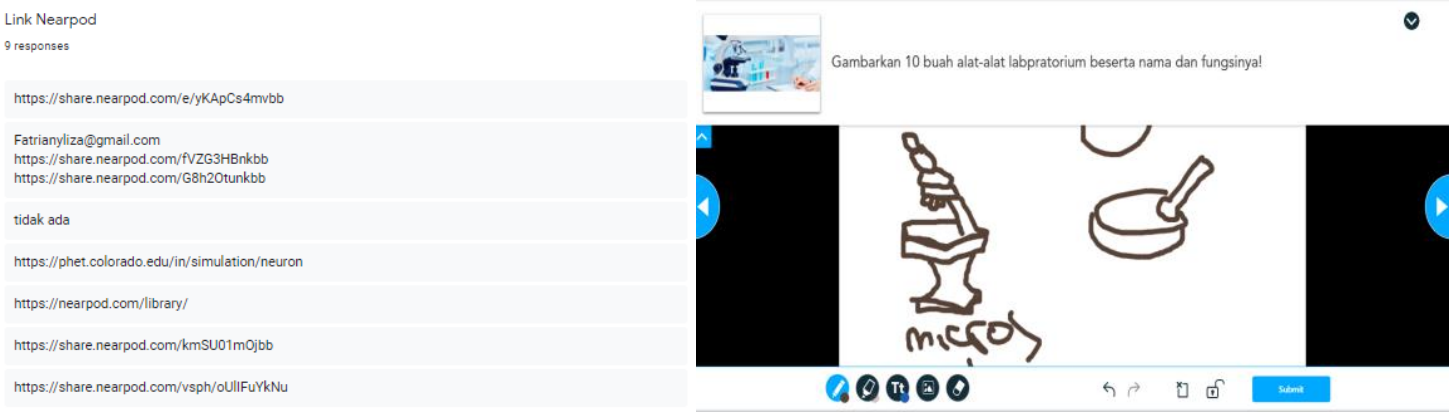

Gambar 4. Hasil tugas Nearpod dari peserta pelatihan dalam salah satu mata pelajaran yang diampu.

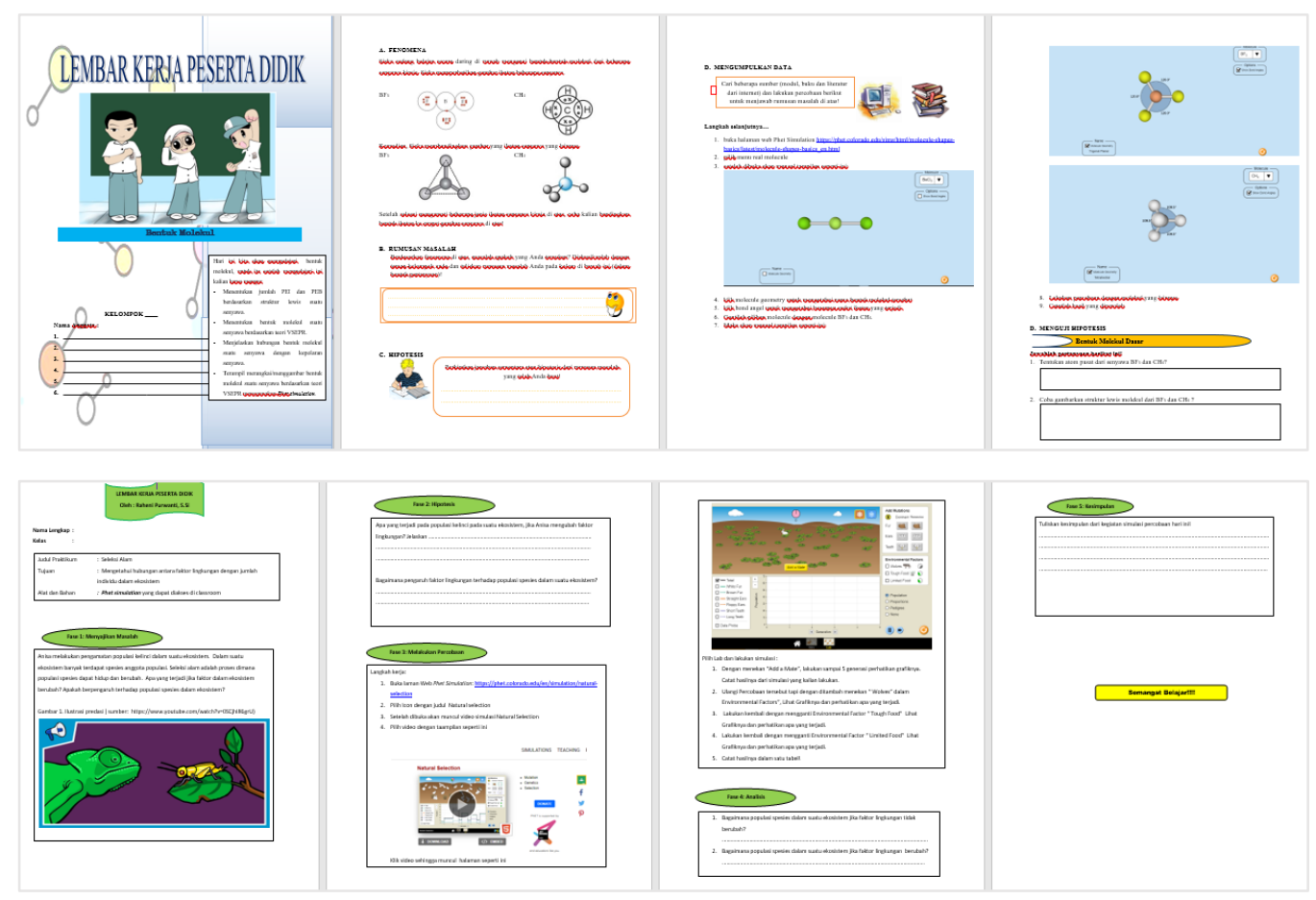

Gambar 5. Hasil pembuatan LKS sederhana untuk mahasiswa dengan mengintegrasikan Laboratorium Virtual PhET. 
PENGENALAN MEDIA PEMBELAJARAN DARING BERBASIS STEM UNTUK GURU IPA DI SMAN 9

BANDAR LAMPUNG

Indah Oktaviani, Ika Agus Rini, Mia Maria Ulfah, Ahmad Dodi Andriana

Volume 1, No. 1, April 2021 hal. 77-88

DOI Artikel : 10.46306/jub.v1i1.16

Hasil analisis dari kegiatan pengabdian kepada masyarakat diperoleh berdasarkan evaluasi dari pelaksanaan yang diberikan. Evaluasi dilakukan dengan pengumpulan tugas yang dilakukan oleh para guru dan juga melalui pretest dan postest menggunakan kuisioner online terhadap penggunaan Nearpod dan juga Laboratorium Virtual PhET untuk mengukur tingkat pemahaman guru mengenai kedua platform tersebut. Hasil evaluasi terhadap tingkat pemahaman kemudian dilakukan untuk menemukan masalah dan juga mencari solusi sebagai evaluasi kegiatan yang dilakukan sebagai dasar perbaikan ke depannya. Berdasarkan hasil pretest untuk mengukur pemahaman Nearpod dan Laboratorium Virtual PhET pada saat pelatihan diperoleh bahwa dari 23 guru yang mengikuti pelatihan hanya sekitar 6\% guru yang pernah mendengar mengenai Nearpod dan 18\% guru pernah mendengar mengenai Laboratorium Virtual PhET, sedangkan sisanya belum pernah mengetahui kedua platform tersebut. Setelah melakukan praktik dan juga membuat tugas peserta kembali diberi posttest untuk mengukur pemahaman. Berdasarkan hasil evaluasi terdapat kenaikan tingkat pemahaman, dan lebih dari $>50 \%$ peserta sepakat bahwa penggunaan Nearpod dan Laboratorium Virtual PhET akan membantu proses pembelajaran terutama dalam menemukan alternatif praktikum virtual yang dapat dilakukan oleh siswa di rumah.

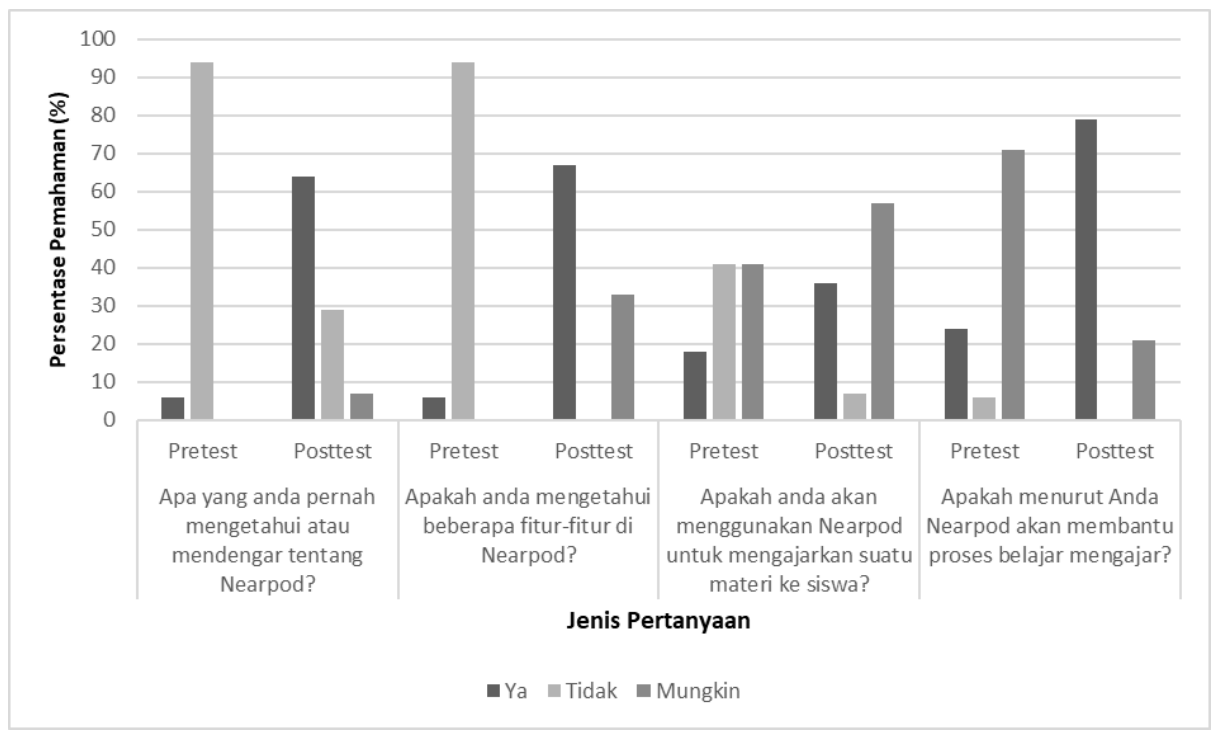

Gambar 6. Hasil evaluasi pemahaman (\%) peserta pelatihan terhadap penggunaan Nearpod yang dilakukan pada awal dan akhir kegiatan pengabdian. 
Indah Oktaviani, Ika Agus Rini, Mia Maria Ulfah, Ahmad Dodi Andriana

Volume 1, No. 1, April 2021 hal. 77-88

DOI Artikel : 10.46306/jub.v1i1.16

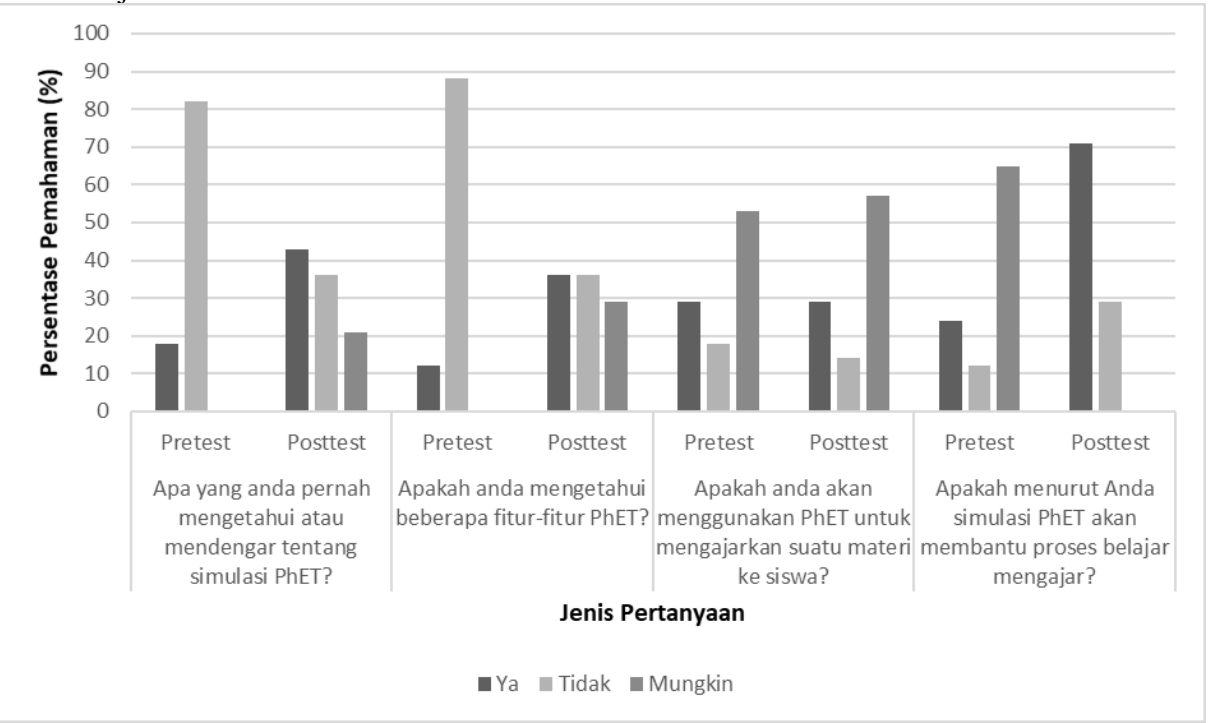

Gambar 7. Hasil evaluasi pemahaman (\%) peserta pelatihan terhadap penggunaan

Laboratorium Virtual PhET yang dilakukan pada awal dan akhir kegiatan pengabdian.

Selain adanya peningkatan pemahaman dan keterampilan dari peserta pengabdian, kegiatan ini telah dipublikasikan di website resmi, social media itera (https:/www.itera.ac.id/dosen-itera-latih-gurusman-9-bandar-lampung-pembelajaran-dan-praktikum-daring/), dan social media program studi Biologi (Instagram: Biologiitera: https://www.instagram.com/p/CHZ-FCTnQay/?igshid=jvzb4fesr3zg). Selain itu, hasil penelitian diresume dalam bentuk poster dan dipamerkan secara virtual dalam acara penghargaan insan cendikia ITERA (gambar 8)

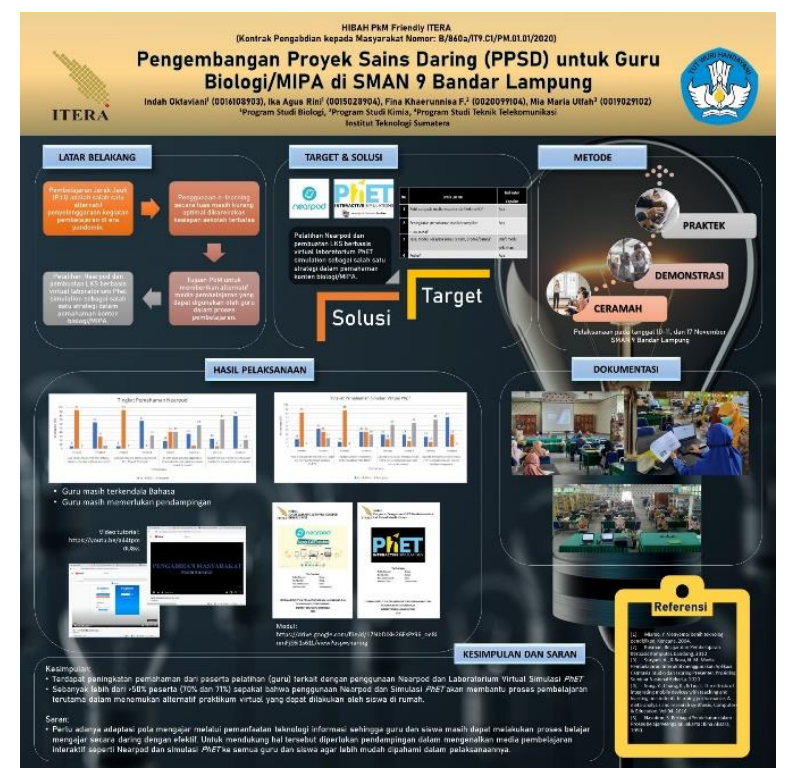

Gambar 8. Poster hasil kegiatan yang telah dipamerkan secara virtual 
PENGENALAN MEDIA PEMBELAJARAN DARING BERBASIS STEM UNTUK GURU IPA DI SMAN 9

BANDAR LAMPUNG

Indah Oktaviani, Ika Agus Rini, Mia Maria Ulfah, Ahmad Dodi Andriana

Volume 1, No. 1, April 2021 hal. 77-88

DOI Artikel : 10.46306/jub.v1i1.16

Berdasarkan kegiatan yang telah dilakukan diperoleh bahwa terdapat peningkatan pemahaman dari peserta pelatihan (guru) terkait penggunaan Nearpod dan Laboratorium Virtual PhET untuk alternatif pengembangan media pembelajaran interaktif yang dapat digunakan dalam proses pembelajaran. Seluruh guru sangat antusias mengikuti pelatihan ini, namun guru dan siswa masih perlu beradaptasi baik dari proses pola belajar mengajar yang hanya sekedar dilakukan di sekolah ke pemanfaatan teknologi informasi sehingga guru dan siswa tetap dapat melakukan proses belajar mengajar secara daring dengan efektif. Untuk mendukung hal tersebut kegiatan berupa pendampingan dalam mengenalkan media pembelajaran interaktif seperti Nearpod dan Laboratorium Virtual PhET ke semua guru dan siswa juga peningkatan kemampuan bahasa inggris karena platform yang ada saat ini rata-rata berasal dari luar negeri.

\section{UCAPAN TERIMA KASIH}

Penulis mengucapkan terima kasih kepada Institut Teknologi Sumatera yang telah memberi dukungan financial terhadap pengabdian ini melalui LP3 Institut Teknologi Sumatera dengan nomor kontrak B/860a/IT9.CI/PM.0I.0I/2020. 
PENGENALAN MEDIA PEMBELAJARAN DARING BERBASIS STEM UNTUK GURU IPA DI SMAN 9

BANDAR LAMPUNG

Indah Oktaviani, Ika Agus Rini, Mia Maria Ulfah, Ahmad Dodi Andriana

Volume 1, No. 1, April 2021 hal. 77-88

DOI Artikel : 10.46306/jub.v1i1.16

\section{DAFTAR PUSTAKA}

Ayob, A., Ibrahim, M. N., Tok, O. E., \& Adnan, M. (20I7). Modul Latihan Pendidikan: Pil Cerdas STEM untuk Prasekolah, Tadika, dan Taska (pertama; N. A. M. M. Nordin,Ed.). Setapak: Al-Ameen Serve Holdings Sdn. Bhd.

Hakami, M. (2020). Using Nearpod as a Tool to Promote Active Learning in Higher Education in a BYOD Learning Environment. Journal of Education and Learning, 2020, ERIC.

Maula \& Fatmawati. (2020). Pengembangan Media Pembelajaran Kayaku (Kayanya Alam Negeriku) Berbasis STEM Kelas IV Sekolah Dasar. Jurnal Ilmiah Sekolah Dasar, 4(I), 97-I05.

Miarso, Y. (2004). Menyemai benih teknologi pendidikan, Kencana.

Muflika, A, A., \& Setiadi, R. (2012). Eksplorasi Pemberdayaan Courseware simulasi PhET untuk membangunketerampilan proses sains siswa SMA. Jurnal Pendidikan Kimia, 17(2), 258-270.

Nasution, S. (1990). Berbagai Pendekatan dalam Proses BelajarMengajar. Jakarta: Bina Aksara.

Rusman. (20/3). Belajar dan Pembelajaran Berbasis Komputer. Bandung.

Sung, Y., Chang, K., \& Liu, T. (20I6). The effects of integrating mobile devices with teaching and learning on students' learning performance: A meta-analysis and research synthesis. Computers \& Education, 94, 252-275.

Suryadi, A., \& Rosa, N. M. (2020). Media Pembelajaran Interaktif menggunakan Aplikasi Camtasia Studio dan Ispring Presenter. Prosiding Seminar Nasional Rekarta.

Zacharia, C.Z \& Jong, D.T. (20I4). One SpecificAdvantage for Virtual Laboratories That May Support the Acquisition of Conceptual Knowledge is That Reality Can Be Adapted to Serve the Learning Process. Reality Can Be Simplified by Taking Out Details. Cognition and Instruction, 32(2), I0I 158. 